\title{
Human DESCI serine protease confers tumorigenic properties to MDCK cells and it is upregulated in tumours of different origin
}

\author{
CG Viloria', JR Peinado', A Astudillo², O García-Suárez², MV González ${ }^{3}, C_{\text {Suárez }}^{3}$ and S Cal ${ }^{*, I}$ \\ 'Departamento de Bioquímica y Biología Molecular, Instituto Universitario de Oncología, Universidad de Oviedo, 33006, Asturias, Spain; ${ }^{2}$ Departamentos \\ de Anatomia Patologica, Hospital Universitario Central de Asturias, Instituto Universitario de Oncología, Oviedo, 33006, Asturias, Spain; \\ 3 y Otorrinolaringología, Hospital Universitario Central de Asturias, Instituto Universitario de Oncología, Oviedo, 33006, Asturias, Spain
}

\begin{abstract}
Proteolysis of the extracellular matrix components plays a crucial role in the regulation of the cellular and physiological processes, and different pathologies have been associated with the loss or gain of function of proteolytic enzymes. DESCI (differentially expressed in squamous cell carcinoma gene I), a member of the TTSP (type II transmembrane serine protease) family of serine proteases, is an epithelial-specific enzyme that has been found downregulated in squamous cell carcinoma of the head and neck region. We describe new properties of DESCI suggesting that this protease may be involved in the progression of some type of tumours. Thus, this enzyme hydrolyses some extracellular matrix components, such as fibronectin, gelatin or fibrinogen. Moreover, Madin-Darby canine kidney (MDCK) cells expressing exogenous human DESCI acquire properties associated with tumour growth such as enhanced motility and an increase of tubular forms in a 3D collagen lattice following HGF treatment. Finally, we generated polyclonal antiDESCI antibodies and immunohistochemical analysis in tissues different from head and neck region indicated that this protease was overexpressed in tumours of diverse origins. Taken together, our results suggest that DESCI could be considered as a potential therapeutic target in some type of tumours.
\end{abstract}

British Journal of Cancer (2007) 97, 201 -209. doi: I0.1038/sj.bjc.6603856 www.bjcancer.com

Published online 19 June 2007

(c) 2007 Cancer Research UK

Keywords: degradome; pericellular proteolysis; extracellular matrix

Pericellular proteolysis is a crucial biological event: membraneassociated proteolytic enzymes are involved in dynamic rearrangements in cell-cell and cell-matrix interactions and deregulation of these activities underlies different pathologies, including cancer (Freije et al, 2003). In fact, the uncontrolled degradation of the extracellular matrix allows the tumour cells to invade surrounding tissues and spread throughout the body. Thus, it is easy to understand that the identification and further characterisation of the proteolytic systems constitute an important challenge for biomedical research, since it may help to identify accurate molecular markers to detect the metastatic disease (Overall and Lopez-Otin, 2002).

The TTSP (type II transmembrane serine proteases) constitute a family of membrane-anchored serine proteases of growing interest since many members have been found widely deregulated during tumour development and progression (Netzel-Arnett et al, 2003). These proteases are structurally complex enzymes containing the catalytic domain at the carboxy terminal region. This domain possesses three highly conserved residues (His, Asp and Ser), which form the catalytic triad of the enzyme. The amino terminal region includes the transmembrane region and an activation domain to switch the protein to its active form. Between these two regions, a variable number of potential protein-protein interaction modular domains can be found. More than 17 members in

*Correspondence: Dr S Cal; E-mail: santical@uniovi.es

Received 4 April 2007; revised 17 May 2007; accepted 22 May 2007; published online 19 June 2007 humans and 20 TTSP genes in mice have been identified at present (Szabo et al, 2005). Although the specific role of most of these enzymes remains unresolved, available information indicates that the TTSP are involved in a variety of key biological functions. Thus, matriptase is an essential enzyme for postnatal survival, epidermal barrier function, hair follicle development and thymic homeostasis in mice (List et al, 2002, 2006); HAT (human airway trypsin-like protease) has been proposed to play a role in host immune defence (Yamaoka et al, 1998); corin regulates blood pressure by activating the cardiac hormone pro-ANP (Yan et al, 2000); and TMPRSS3 has been suggested to be involved in inner ear development (Guipponi et al, 2002). Likewise, the role of the TTSP in tumour growth, cancer invasion and metastasis processes are being increasingly documented for proteases such as matriptase (List et al, 2005), matriptase-2 (Velasco et al, 2002) and hepsin (Hobson et al, 2004; Klezovitch et al, 2004).

The HAT/DESC constitutes a phylogenetically related subfamily of TTSP (Netzel-Arnett et al, 2003) with five DESC1 (differentially expressed in squamous cell carcinoma gene 1)-like genes clustered within a region in the chromosome 4q (Behrens et al, 2004; Hobson et al, 2004). DESC1 was identified through the reduced levels of associated mRNA present in tumours from diverse sites in the head and neck region when compared with corresponding normal tissue (Lang and Schuller, 2001). Recently, the protein has been reported to be downregulated in tissues from the oropharyngeal cavity during the squamous cell carcinoma progression and upregulated during normal epithelial differentiation (Sedghizadeh et al, 2006). 
Our interest in genes differentially expressed in head and neck carcinomas has directed our attention to DESC1. In this report we describe new insights about the biochemical and functional properties of this protease indicating that this enzyme could be involved in tumour progression. Thus, this protease can hydrolyse different extracellular matrix components and also can activate pro-uPA. Likewise, different assays using Madin-Darby canine kidney (MDCK) cells stably transfected with DESC1 full-length cDNA showed that this enzyme enhances cell motility. Moreover, these cells form long extensions when they are grown in 3D collagen lattice, which represents a partial epithelial-mesenchymal transition (O'Brien et al, 2002). Finally, the generation of antibodies towards its catalytic domain has allowed us to find that DESC1 is overexpressed in a variety of previously untested tumours of different origins.

\section{MATERIALS AND METHODS}

\section{Molecular cloning of human DESC1}

The DESC1 cDNA sequence (GenBank accesion number AF064819) was used as query to carry out a search in the NCBI human Expression Sequence Tag (EST) database (www. ncbi.nlm.nih.gov/ Blast/Blast.cgi). An EST sequence from a skin cDNA library, BG697702, was identified and purchased from the Geneservice Ltd (Cambridge, UK). This EST served as template for a PCR amplification of the human DESC1 full-length cDNA using specific primers. The amplification product was cloned into the EcoRV site of the mammalian vector pcDNA3 containing a haemagglutinin (HA) epitope at the $\mathrm{C}$ terminus to give a pcDNA-HA-DESC1 vector. The identity of the sequence was confirmed by automated nucleotide sequencing.

\section{Production and purification of recombinant catalytic domain DESC1, generation of polyclonal antibodies and Western blot analysis}

A 695-bp fragment of the DESC1 cDNA encoding the entire serine protease domain was generated by PCR amplification using the EST BG697702 as template and the specific oligonucleotides desc3F $\left(5^{\prime}\right.$-ATCGTTGGTGGGACAGAAGTAG-3') and desc1R (5'-GATAC CAGTTTTTGAAGTAATCCAG-3 ${ }^{\prime}$ ). PCR amplification conditions, cloning in pGEX-3X vector, and expression and purification of DESC1 catalytic domain fused to GST were carried out as described to characterise matriptase-2 (Velasco et al, 2002), with minor modifications. The resulting expression vector (pGEX-3XDESC1) was transformed into BL21(DE3)pLysS competent E. coli cells, and expression was induced by the addition of isopropyl1-thio- $\beta$-D-galactopyranoside (final concentration, $0.5 \mathrm{~mm}$ ) followed by further incubation for $4-6 \mathrm{~h}$ at $30^{\circ} \mathrm{C}$. The cells were collected by centrifugation, washed and resuspended in 0.05 volumes of PBS. Finally, the cells were lysed by sonication and centrifuged at $20000 \mathrm{~g}$ for $20 \mathrm{~min}$ at $4^{\circ} \mathrm{C}$. The soluble extract was loaded on a glutathione-Sepharose 4B column (GE Healthcare, Uppsala, Sweden), and the glutathione $S$-transferase GST-DESC1 fusion protein eluted with glutathione elution buffer $(10-\mathrm{mm}$ reduced glutathione in $50 \mathrm{~mm}$ Tris- $\mathrm{HCl}, \mathrm{pH} \mathrm{8.0)}$, following the manufacturer's instructions. Finally, the purified GST-DESC1 fusion protein was used for enzymatic assays. GST alone was also produced using same experimental procedures to be used as a control in further assays. Recombinant DESC1 catalytic domain was likewise employed to generate polyclonal antibodies against DESC1, following the same strategy used to generate antipolyserase- 1 antibodies (Cal et al, 2003). For Western blot analysis, proteins were separated on SDS-PAGE gels, blotted onto nitrocellulose membranes and incubated following standard procedures.

\section{Gelatin zymography}

A $0.5 \mu \mathrm{g}$ of GST or GST-DESC1 were mixed with SDS sample buffer in absence of reducting agents. Then, and without boiling, the samples were subjected to electrophoresis in a $12 \%$ acrylamide gel containing $0.2 \%$ gelatine. Gel was run at $10 \mathrm{~mA}$, washed in $2.5 \%$ Triton X-100 for $3 \mathrm{~h}$ and incubated at $37^{\circ} \mathrm{C}$ for $16 \mathrm{~h}$ in $20 \mathrm{~mm}$ Tris$\mathrm{HCl} \mathrm{pH} \mathrm{7.4,} \mathrm{and} 5 \mathrm{mM} \mathrm{CaCl}_{2}$. After incubation, the gel was stained with Coomassie Brilliant Blue R-250, and destained in $30 \%$ methanol and $10 \%$ acetic acid. Gelatinolyc activities were detected as clear bands in the blue background. As positive control $5 \mu \mathrm{l}$ of HT1080 conditioned medium were added to one of the lanes (Stanton et al, 1998).

\section{Enzymatic assays}

To detect the enzymatic activity of the purified enzyme, recombinant DESC1 was incubated with $5 \mu \mathrm{g}$ of different proteins including type I laminin, type I gelatin, fibronectin and fibrinogen or $1 \mu \mathrm{g}$ of pro-uPA. Reactions were carried out and visualised as described in Velasco et al (2002). For the inhibition assays, recombinant protein was previously incubated for $30 \mathrm{~min}$ at $37^{\circ} \mathrm{C}$ with $20 \mu \mathrm{M}$ AEBSF, $0.2 \mathrm{~mm}$ TPCK, $2.5 \mathrm{~mm}$ EDTA or $35 \mu \mathrm{M}$ E64, and the subsequent reactions were performed using fibrinogen as substrate. Synthetic peptides Boc-Gln-Gly-Arg-AMC and Boc-GlnAla-Arg-AMC were likewise used to detect enzymatic activity, and assays were carried out using $10 \mu \mathrm{m}$ of substrate and $40 \mathrm{ng}$ of DESC1. Inhibition was likewise tested preincubating the enzyme for $30 \mathrm{~min}$ at $37^{\circ} \mathrm{C}$ with $2.5 \mathrm{~mm}$ EDTA; 20,200 and $500 \mu \mathrm{M} \mathrm{AEBSF}$; $35 \mu \mathrm{M}$ E-64; $20 \mathrm{nM}$ antitrypsin or $20 \mathrm{nM}$ antichymotrypsin. Initial velocities were calculated using the analysis package FL WinLab 2.01 (PerkinElmer Life Sciences, Waltham, MA, USA), and data were fitted to the Michaelis-Menten equation using GraFit version 4.0 (Erithacus, Surrey, UK). Purified GST was used as a negative control under the same experimental conditions.

\section{Cell culture conditions, transfection and immunofluorescence}

MDCK cell line was routinely maintained in DMEM media supplemented and $10 \%$ fetal bovine serum (FBS) (Invitrogen, Karlsruhe, Germany). MDCK clones expressing recombinant DESC1 (MDCK/DESC1 cells) and MDCK transfected with an empty vector (control cells) were obtained by transfection using the LipofectAMINE reagent (Invitrogen). Stable transfection in MDCK cells was carried out in DMEM medium containing $800 \mu \mathrm{g} \mathrm{ml}^{-1}$ of geneticin. To detect recombinant DESC1, cells were fixed with $4 \%$ paraformaldehyde in phosphate-buffered saline, and blocked with $15 \%$ of FBS. Then, the slides were incubated for $2 \mathrm{~h}$ with a primary anti-HA (Roche, Basel, Switzerland) or anti-DESC1 antibody, followed by $2 \mathrm{~h}$ of incubation with a secondary fluorescein-conjugated sheep anti-mouse antibody (GE Healthcare) or a Texas Red-conjugated donkey anti-rabbit secondary antibody (GE Healthcare), respectively. In all samples, $4^{\prime}, 6^{\prime}$ diamino-2-phenylindole hydrochloride was added at $100 \mathrm{ng} \mathrm{ml}^{-1}$ to visualise DNA in the cell nucleus. Images were obtained using a fluorescence microscopy Axiovert 200 (Zeiss, Jena, Germany) and a digital camera. MDCK cells transfected with a vector containing the polyserase-1 cDNA (Cal et al, 2003) were used as negative control.

\section{Scrape-wound migration assay and matrigel invasion assay}

Monolayers of MDCK/DESC1 cells or control cells were scraped with a pipette tip in a single stripe. The wounded cultures were incubated at $37^{\circ} \mathrm{C}$ and cells migrating into the scraped area were imaged at different times. Tumour cell invasion assay was performed in cell culture chambers coated with matrigel (BD 
Biosciences, San Jose, CA, USA) following manufacturer instructions. In brief, MDCK/DESC1 transfected cells and control cells were seeded $\left(5 \times 10^{4}\right.$ cells well $\left.^{-1}\right)$ in DMEM medium containing $5 \% \mathrm{BSA}$ and $50 \mathrm{ng} \mathrm{ml}^{-1}$ HGF. A $10 \%$ FBS was additionally included in the lower chambers to act as a chemoattractant. After $48 \mathrm{~h}$ of incubation, the cells on the lower membrane surface were fixed and stained with $0.5 \%$ crystal violet in $10 \%$ methanol. Randomly selected microscopic fields (magnification $\times 20$ ) were imaged to calculate the average number of occupied pores per microscopic field. Data are expressed as mean \pm s.e.m. Differences in value distribution were statistically validated using the two-tailed $t$-test for unpaired data. Statistical analyses were performed using the program GraphPad Prism 3 for Windows. Difference was considered to be significant at values lower than $P<0.05$.

\section{Analysis of morphological changes in a 3D collagen lattice}

MDCK/DESC1 cells or control cells were assayed to evaluate their ability to form tubular structures within a 3D Collagen Cell Culture System (Chemicon International, Temecula, CA, USA), following manufacturer instructions. Briefly, $1 \times 10^{3}$ cells were mixed with a neutralised chilled collagen solution, dispensed into 96-well plates and incubated at $37^{\circ} \mathrm{C}$ until gelification. Culture medium containing $3 \% \mathrm{FBS}$ and HGF $\left(30 \mathrm{ng} \mathrm{ml}^{-1}\right.$ ) or without HGF (control) was added to the wells and renewed every day for 7 days. Cultures were photographed after 7 days under phase contrast using an inverted microscope. To semiquantify the formation of tubular structures, 15 microscopic fields were randomly selected per experimental condition. Then, the number of tube structures was determined, and their length was also measured by using image analysis software.

\section{Immunohistochemistry}

Human tissues were obtained as formalin-fixed, paraffinembedded tissue sections from the archives of the tumour bank from the Hospital Universitario Central de Asturias (HUCA, Oviedo, Asturias, Spain). Tissue arrays were likewise used to evaluate DESC1 expression according to the histological type of cancer. After dewaxing and rehydrating, samples were blocked in $15 \%$ goat serum and then incubated overnight with anti-DESC1 antibody $(1: 150)$. Then, sections were incubated with an EnVision System labelled polymer-HRP anti-rabbit (DAKO, Glostrup, Denmark), and the staining was completed by incubation with diaminobenzidine colorimetric reagent (DAKO), followed by counterstaining with hematoxylin. Finally, the slides were dehydrated and mounted. Controls included samples that were incubated with a preimmune serum.

\section{RESULTS}

\section{Production of the recombinant DESC1 catalytic domain} and generation of polyclonal antibodies

Molecular cloning of the human DESC1 full-length cDNA was carried out by PCR amplification using EST BG697702 as template. The amplified product was 1269-bp long and contained the open reading frame reported previously (Lang and Schuller, 2001). The catalytic domain of this protein was expressed independently from the rest of the molecule following a strategy previously used to analyse other members of this family of proteases (Velasco et al, 2002). To this end, a 695-bp fragment coding for this region was PCR amplified and subcloned into the pGEX-3X vector generating the plasmid pGEX-3X-DESC1, which allows the expression of this catalytic domain fused to the glutathione-S-transferase. This region contains 231 amino acids $(25.4 \mathrm{KDa})$, starting at the Ile191 after the putative proteolytic activation site (Arg190) within the conserved R-IVGG motif of this type of serine proteases
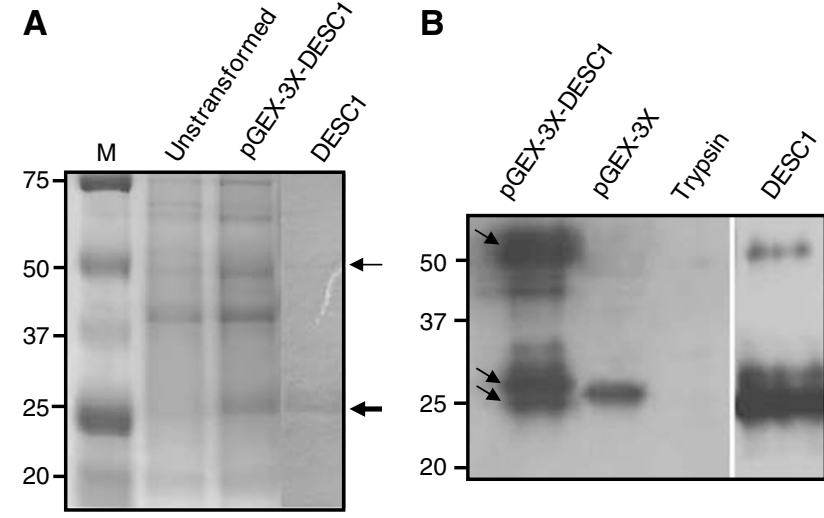

Figure I Production of recombinant DESCI. (A) Untransformed BL2I (DE3)pLysE E. coli cells (lane 2) and cells transformed with pGEX3X-DESCI after IPTG induction (lane 3) or purified DESCI (lane 4) were analysed by SDS-PAGE. The sizes of molecular weight marker $(\mathrm{kDa})$ are indicated on the left (Lane I, M). DESCI fused to GST is indicated with a thin arrow. Position for DESCI released from GST is indicated with a thick arrow. (B) Western blot analysis of the proteins using the anti-DESCI antibodies generated in this work. Fused GST + DESCI protein $(50.4 \mathrm{kDa})$ and released GST $(26 \mathrm{kDa})$ and DESCI $(25.4 \mathrm{kDa})$ are indicated with arrows (lane I). The generated antibodies detect GST expressed alone (lane 2), but not trypsin (lane 3). Lane 4, purified products eluted from a glutathione-Sepharose 4B column.

(Netzel-Arnett et al, 2003). A $51.4 \mathrm{kDa}$ band corresponding to the combined molecular masses of GST $(26 \mathrm{kDa})$ and DESC1 $(25.4 \mathrm{kDa})$ was detected by SDS-PAGE (Figure 1A). This fusion protein was purified by affinity chromatography on a glutathioneSepharose 4B column (Figure 1A). DESC1 was not released from the GST with Factor Xa to avoid any minor contamination of this protease in the subsequent analysis of DESC1 activity. However, DESC1 was spontaneously released from the GST probably as a consequence of an autocatalytic processing during the course of the different assays (Figure 1A). This effect has been described for other TTSPs such as matriptase (Takeuchi et al, 1999), matriptase2 (Velasco et al, 2002), matriptase-3 (Szabo et al, 2005), TMPRSS2 (Afar et al, 2001) and TMPRSS3 (Guipponi et al, 2002).

The DESC1 protein fused to GST was likewise used to generate rabbit polyclonal antibodies against human DESC1. The specificity of these antibodies was tested during the protein purification process by Western blot (Figure 1B). As expected from an autoactivation process, immunoreactive bands of 51.4, 26 and $25.4 \mathrm{kDa}$ were clearly visible, corresponding to the fusion protein $(\mathrm{GST}+\mathrm{DESC} 1)$, and the released GST and DESC1, respectively. A $0.5 \mu \mathrm{g}$ of trypsin was added to the gel to be used as negative control. The produced antibodies also recognise the mix of GST and DESC1 after purification by affinity chromatography. This result reveals the ability of the generated antibody to recognise DESC1.

\section{DESC1 is a catalytically active serine protease that cleaves} protein substrates

Enzymatic activity of DESC1 was demonstrated through different assays. Thus, a gelatine zymogram indicated that this serine protease displayed a prominent gelatinolytic activity. By contrast, the GST alone, expressed and purified in parallel to be used as a negative control, did not show any activity (Figure 2A). Then, DESC1 recombinant protein was incubated with different protein substrates, including extracellular matrix protein components, and the products of the reactions were visualised by SDS-PAGE gels. As Figure 2A shows, DESC1 hydrolyses fibronectin, gelatin, proUPA, but not laminin. The enzyme may likewise hydrolyse 

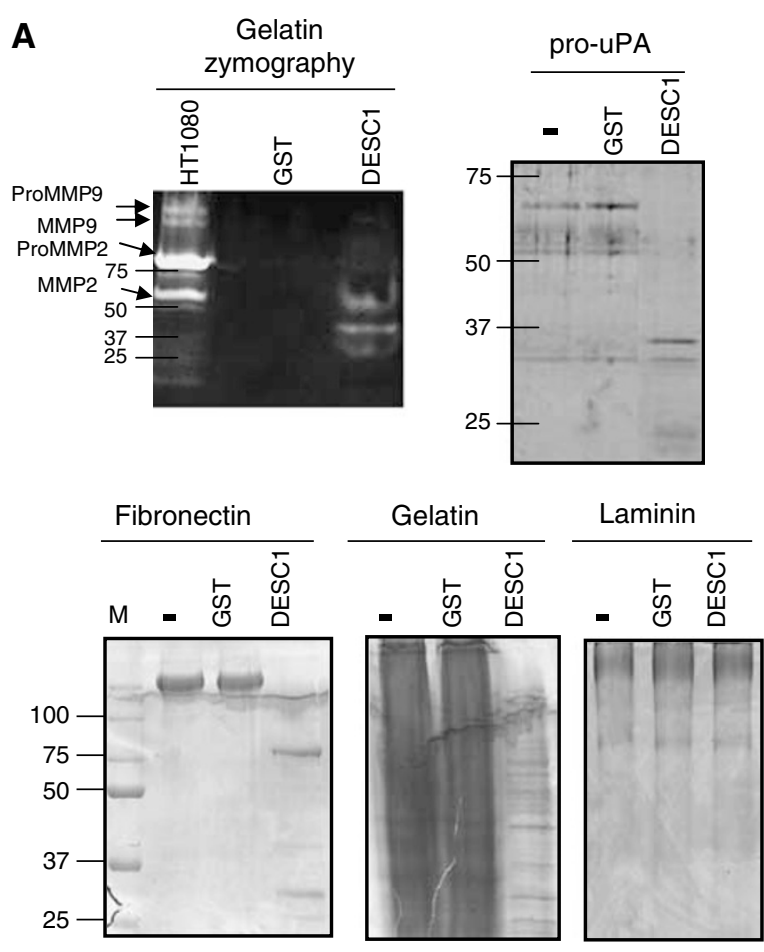

B

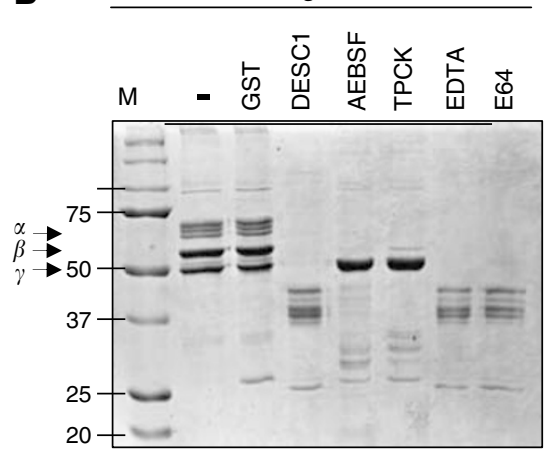

C

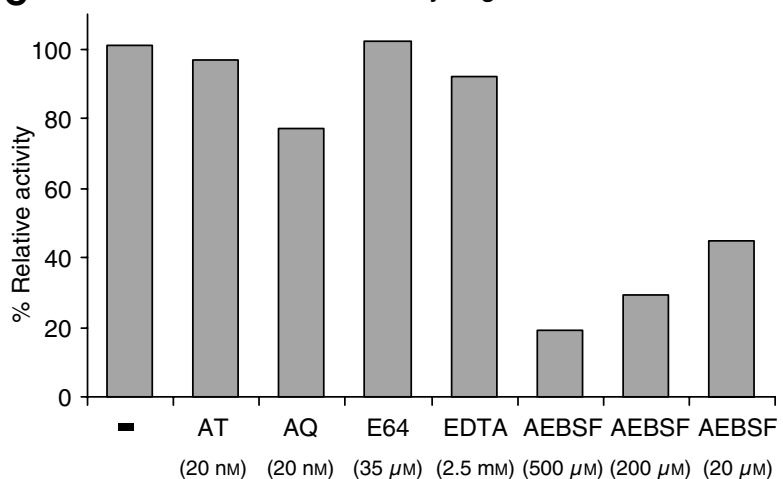

Figure 2 Analysis of enzymatic properties of DESCI. (A) Gelatin zymography: purified DESCI has gelatinolytic activity. Purified GST was used as negative control and $5 \mu \mathrm{l}$ of the conditioned medium of the cell line HTI080 was used as positive control. ProMMP9 and MMP9, and ProMMP2 and MMP2 gelatinolytic activities are indicated with an arrow. Fibronectin, type I gelatin, laminin and pro-uPA were incubated alone $(-)$ or in presence of purified GST or DESCl. Molecular weight markers $(\mathrm{M}, \mathrm{kDa})$ are shown on the left and for pro-uPA, on the right. (B) Fibrinogen was also incubated alone (-) or in presence of GST (lane 2) or DESCI (lane 3). Preincubation for 30 min at $37^{\circ} \mathrm{C}$ with $100 \mu \mathrm{M}$ AEBSF (lane 4), $0.2 \mathrm{mM}$ TPCK (lane 5), $2.5 \mathrm{mM}$ EDTA (lane 6 ) or $10 \mu \mathrm{M}$ E64 (lane 7) was carried out before incubation with the substrate. GST and DESCI positions are indicated on the right. (C) Inhibition assay using the synthetic fluorescent peptide Boc-GIn-Gly-Arg-AMC as susbstrate. Recombinant DESCI was preincubated in the presence or absence of the protease inhibitors as indicated in Material and Methods. (-) indicates absence of inhibitor.

fibrinogen (Figure 2B). However, proteolytic activity on these substrates was not detected when incubated with GST alone (Figure $2 \mathrm{~A}$ and $\mathrm{B}$ ). These results suggest a potential role for DESC1 in the degradation and/or remodelling of the extracellular matrix ECM. Furthermore, the cleavage products obtained from DESC1 incubation with the single-chain pro-uPA (Figure $2 \mathrm{~A}$ ) resembled the size of the two chain forms $(20$ and $33 \mathrm{kDa})$ of the enzymatically active uPA capable of interacting with the uPA receptor, a system which is known to play a critical role in cancer progression. Preincubation of DESC1 with serine proteases inhibitors such as AEBSF or TPCK produces a considerable reduction in the $\gamma$-chain of fibrinogen cleavage (Figure 2B). By contrast, this effect was not observed when the preincubation was carried out with inhibitors for other types of proteases like EDTA and E64 (Figure 2B).

We have also examined the ability of DESC1 to degrade peptide substrates (Figure 2C). The predicted preferential cleavage for other TTSPs at amino acid residues with positively charged side chains was tested for DESC1 using two synthetic AMC-coupled peptides with Arg residues as P1 site. The results indicated that DESC1 was able to cleave Boc-Gln-Gly-Arg-AMC more efficiently than BocGln-Ala-Arg-AMC (data not shown), with a $K_{\mathrm{m}}$ of $134 \mu \mathrm{M}$ and $V_{\max }$ of $3 \times 10^{-4} \mu \mathrm{M} \mathrm{s}^{-1}$. The proteolytic activity of DESC1 using the first peptide substrate was inhibited by preincubation with the serine proteinase inhibitor AEBSF (above $80 \%$ inhibition at $500 \mu \mathrm{M}$ ). These results confirm the serine protease nature of DESC1. 
A
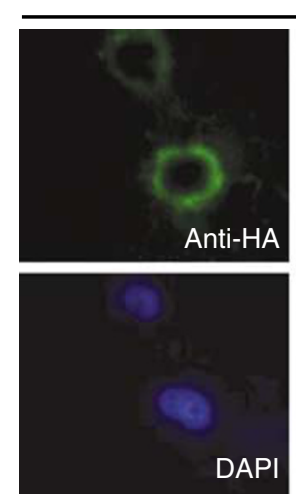

DAP
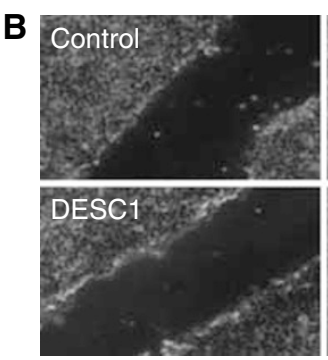

$1 \mathrm{~h}$
DESC1
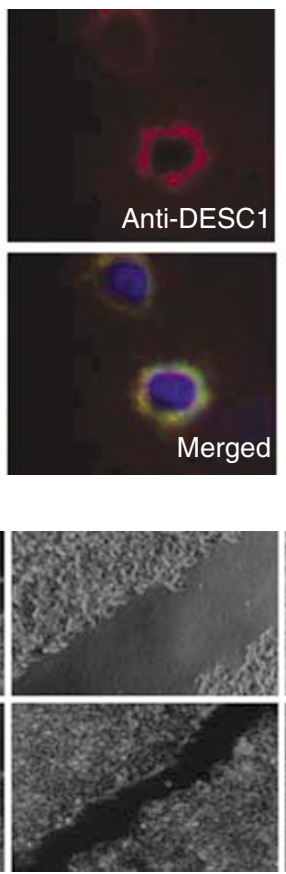

$5 \mathrm{~h}$

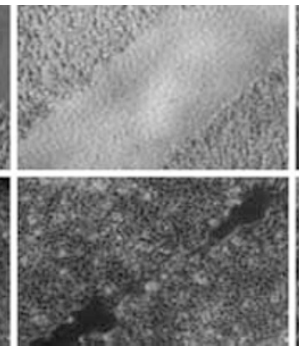

$8 \mathrm{~h}$
Polyserase-1
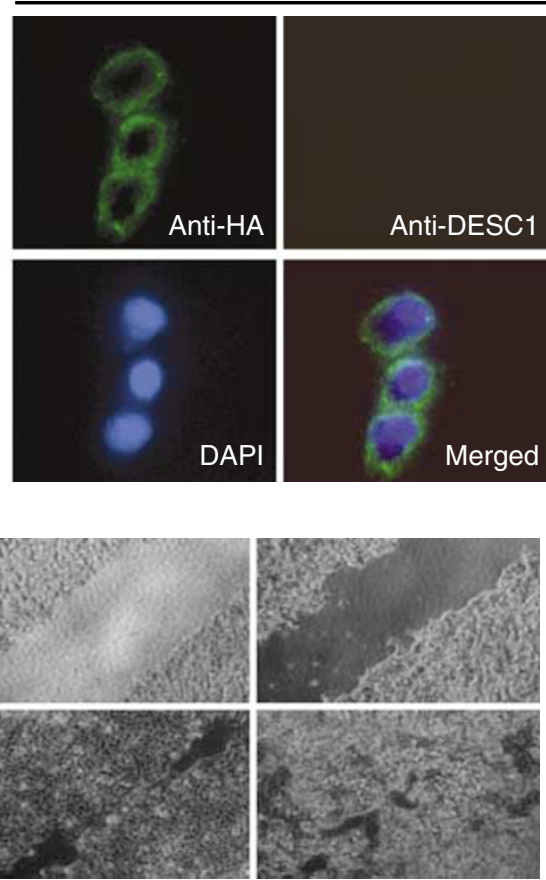

$24 \mathrm{~h}$
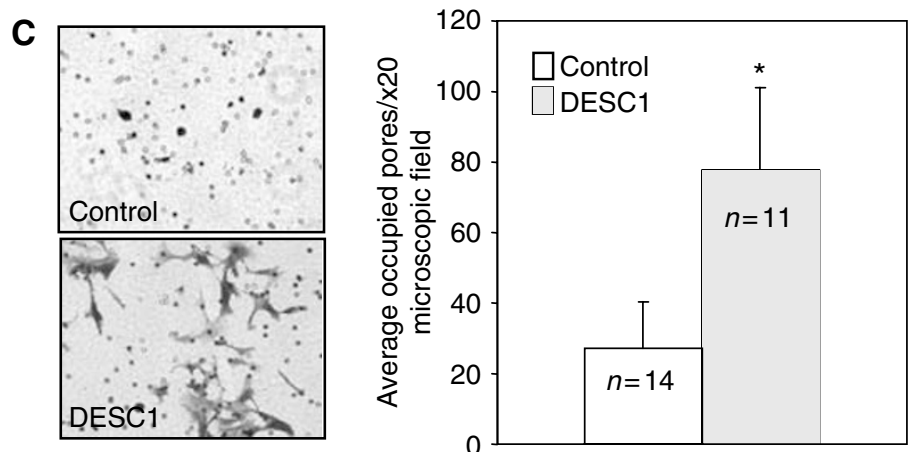

Figure 3 Membrane localisation and effect of DESCI expression on MDCK cells motility. (A) Immunocytochemical detection of recombinant DESCI expression in MDCK cells. The images were captured by fluorescence microscopy of MDCK cells transfected with pcDNA-HA-DESCI vector or with the same pcDNA3-HA plasmid containing the cDNA for polyserase- I. Immunofluorescent detection of anti-HA antibodies was carried out with a fluoresceinconjugated anti-mouse antibody, and detection of anti-DESCI antibodies with a Texas Red-conjugated anti-rabbit antibody. Result shows the membrane localisation of DESCI. (B) Wound closure assay. Scrape wounds were made in confluent monolayers of cells stably transfected with vector containing DESCI or control vector. Cell layers were imaged at the indicated times. (C) Matrigel invasion assay. Invasion capacity of MDCK/DESCI cells and control transfectants were analysed by a Matrigel invasion assay after $48 \mathrm{~h}$ of incubation. Number of occluded pores by the cells and by the control cells transfected were counted and represented on the right $(* P<0.000 \mathrm{I})$. $N$ indicates the number of microscopic fields analysed.

\section{Membrane localisation and effect of DESC1 expression on motility of MDCK cells}

MDCK cells were stably transfected with DESC1 cDNA (MDCK/ DESC1 cells) to examine the possible contribution of this protease to cellular invasiveness. Expression of exogenous DESC1 was confirmed by immunostaining using the generated anti-DESC1 antibody and an anti-HA antibody (Figure 3A). MDCK cells transfected with a vector containing the cDNA encoding for polyserase-1 was used as control. In all cases, the samples were not permeabilised to detect the presumably extracellular catalytic domain. Two positive clones were selected for further analysis and results were equivalent in both cases. These assays were carried out using two different approaches. First, these clones were grown to confluence to carry out a scrape-wound migration assay. After in vitro 'wounding' of the cell monolayers, the cultures allowed to grow and wound closures were visualised at different times. As can be seen in Figure 3B, MDCK/DESC1 migrated to nearly cover the wound site within $8 \mathrm{~h}$. By contrast, wound closure was incomplete after the same time interval in control cells (MDCK cells stably transfected with an empty vector), remaining almost intact after $24 \mathrm{~h}$. These data suggest that DESC1 may be involved in migration and motility properties of these cells.

The second approach consisted in analysing cell behaviour in a matrigel invasion assay. In this case, we used invasion chambers to evaluate the ability of MDCK/DESC1 cells to degrade matrigel. After $48 \mathrm{~h}$ of incubation and 10\% FBS used as chemoattractant, the migratory cells were stained and the number of pores occupied in randomly selected $20 \times$ microscopic fields were counted and averaged (Figure 3C). A significant difference was observed 
between the levels of migration of the MDCK/DESC1 when compared to the MDCK cells transfected with the empty vector. Likewise, MDCK/DESC1 cells not only could extravasate the matrix but they also showed a branched and more elongated morphology than control cells. This tendency was also apparent at $24 \mathrm{~h}$ of incubation and also when lowering the chemoattractant concentration to $2 \%$ (not shown).

\section{MDCK cells expressing DESC1 form cysts that display long extensions in a $3 \mathrm{D}$ collagen lattice}

MDCK cells have been reported to form cysts and develop branching tubules following HGF stimulation when they are grown embedded in collagen gel network (Ridley et al, 1995). We wanted to evaluate the ability of DESC1 to induce these effects in MDCK cells. To test this, MDCK/DESC1 or control cells were mixed with a collagen gel and allowed to grow. These assays were carried out with or without HGF treatment and the cultured cells were imaged after 7 days. As can be seen in Figure 4A, MDCK/DESC1 cells form cysts from which surface-long branching extensions are clearly detectable following HGF stimulation. In terms of number of tube structures, DESC1 expression induces the formation of more tubes than control cells (average of 6.5 vs 3.5, respectively). However, the difference is considerably higher in terms of tube lengths $(60.8 \mu \mathrm{m} v s \quad 10.5 \mu \mathrm{m})$. Moreover, the formation of these extensions clearly diminished with the presence $50 \mu \mathrm{M}$ of the serine proteinase inhibitor AEBSF (Figure 4A and B). These data would indicate that DESC1 expression enhances the capacity of MDCK to invade a collagen matrix following HGF stimulation.

\section{Analysis of DESC1 expression in normal and tumoral human tissues}

DESC1 expression in oropharyngeal cavity correlates directly with keratinocyte differentiation and inversely with squamous cell

A

\begin{tabular}{|cccc|}
\hline HGF & - & + & + \\
AEBSF & - & - & + \\
\hline
\end{tabular}
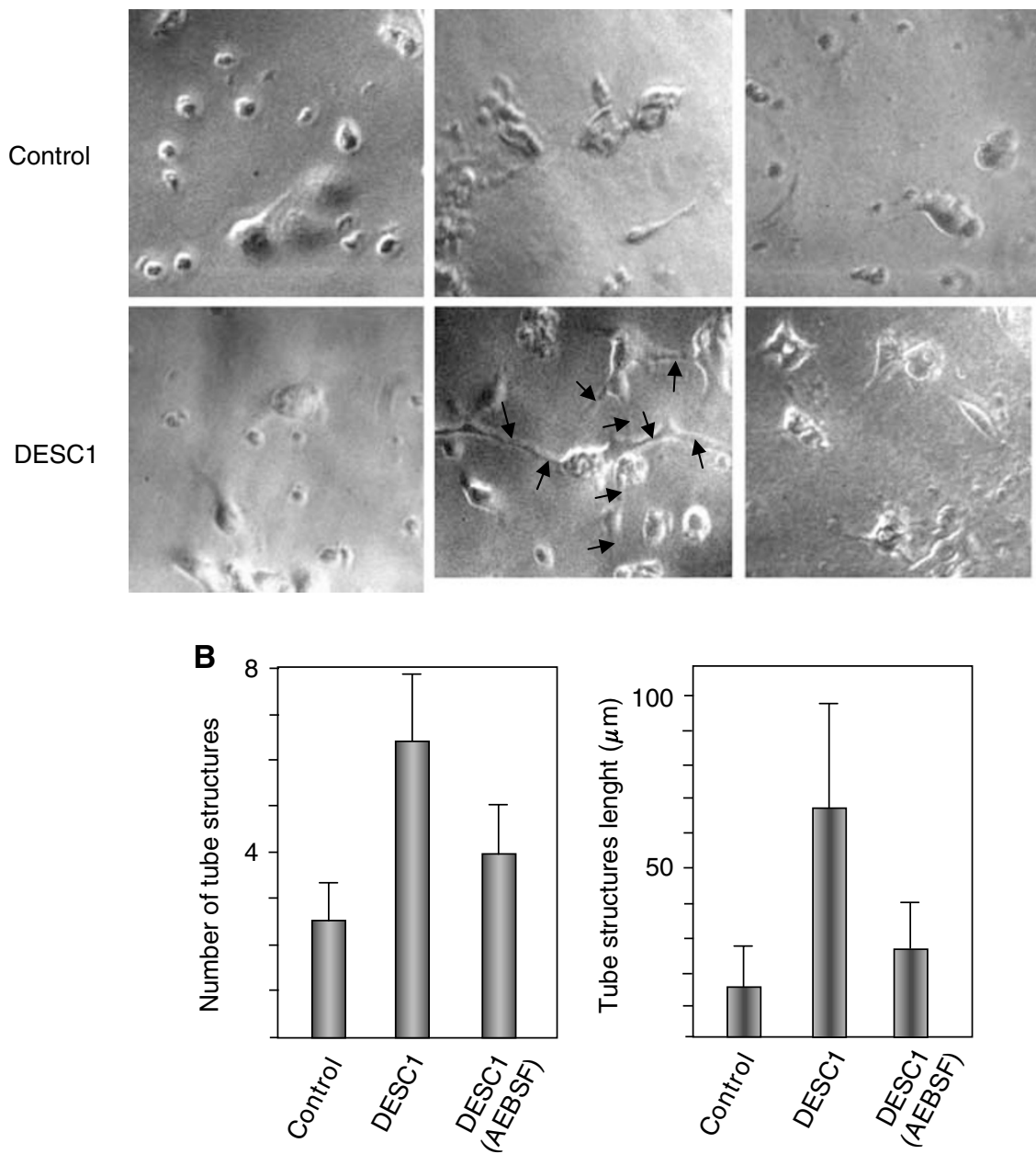

Figure 4 (A) HGF-stimulated MDCK/DESCl cells embebbed in collagen gel form tubular structures. MDCK cell clones stably transfected with control vector or expressing DESCI were cultured in a type I collagen matrix for 7 days in presence $(+)$ or in absence $(-)$ of $30 \mathrm{ng} \mathrm{ml}^{-1}$ of $\mathrm{HGF}$, and in the presence $(+)$ or absence $(-)$ of $50 \mu \mathrm{M}$ of AEBSF. The branching extensions formed by MDCK/DESCI cells are indicated by arrows. (B) Quantification of the number and length of tubular structures of 15 randomly selected microscopic fields following HGF stimulation. 


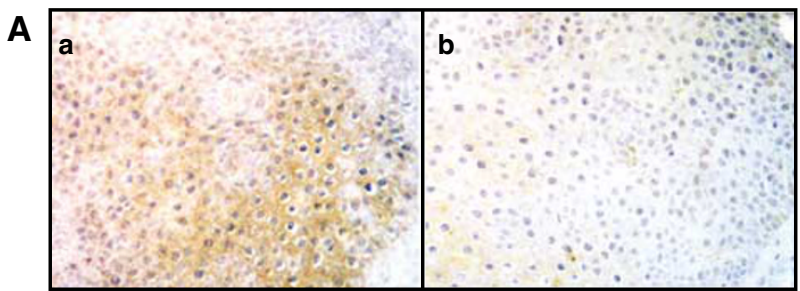

B

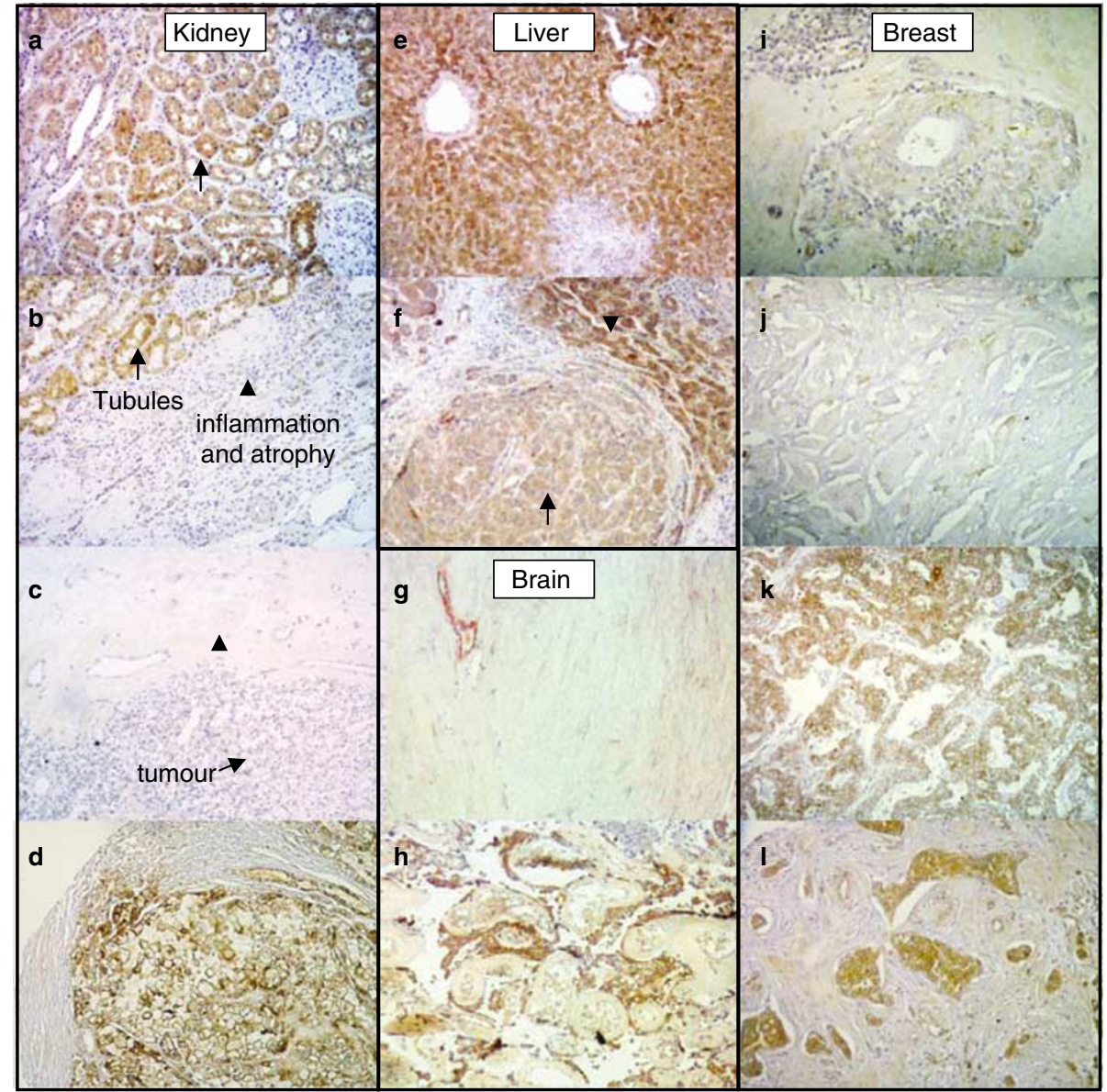

Figure 5 DESCl expression in kidney, liver, brain and breast normal and tumour tissues. (A) (a) Immunostaining of the epithelial component of a larynx tissue sample using the antibody generated in this work. (b) Immunostaining performed with a preimmune control serum does not show this pattern. (B) (a-d) $I H C$ in kidney. (a) Normal kidney showing DESCI expression in tubules (arrow). (b) Reactive tubules show positive expression (arrow), the proximal inflammated and atrophical region is negative (arrowhead in b and c), and the derived well-differentiated clear cell tumour in (c) is negative (see arrow). (d) Sample from a tissue array slide showing positivity in a poorly differentiated renal clear cell tumour. Note the negativity in the stroma. (e-f) IHC in liver. (e) Liver tissue showing intense signal in the pericentral hepatocytes. ( $f$ ) Renal invasive hepatocarcinoma corresponding to the same specimen as in (e). Staining diminishes in the nodal satellite (arrow) that compresses some positive normal hepatocytes (arrowhead). (g-h) IHC of the brain. (g) Leptomeninges (dura mater) showing negative expression of DESCl. (h) Atypical meningioma showing positivity. (i-l) IHC of breast. (i) Reactive benign breast tissue showing slight positivity surrounding a negative duct. (j) Negative immunostaining in a ductal micropapilar breast tumour. (k) Positivity in a ductal breast carcinoma. (l) Positivity in a lobular breast carcinoma. Magnification was $20 \times$ and counterstaining was with haematoxylin.

carcinoma progression (Sedghizadeh et al, 2006). However, our data suggest that DESC1 could be implicated in the development and/or progression of some type of tumours. These facts prompted us to extend the study of DESC1 expression to different type of tissues including kidney, liver, brain and breast. This study was carried out using the antibodies generated in this work and, to determine optimal antibody dilutions, we first employed a normal larynx tissue sample that showed an immunostaining of the epithelial component (Figure 5A). This signal was absent when the sample was treated with preimmune serum (Figure 5A). Then, we employed paraffin-embedded tissue and tissue arrays that included specimens of normal and squamous carcinoma, adenocarcinomas and other tumours of different histological type. Figure $5 \mathrm{Ba}-\mathrm{d}$ shows DESC1 expression in normal and tumoral kidney. Normal tubule epithelial cells showed intense expression (Figure $5 \mathrm{Ba}$; arrow). Inflammation and atrophy represented in Figure $5 \mathrm{Bb}$ and $\mathrm{c}$ (arrowhead) correlate with a dramatic loss of expression that is also apparent in the derived clear cell tumour (Figure 5Bc, arrow). 
We tested two negative renal tumours versus six positive cases (see example in Figure 5Bd). In the case of the liver, Figure 5Be reveals intense staining in normal hepatocytes. A nodule from an invasive hepatocarcinoma displays a clear diminished expression (arrow in Figure 5Bf). More intense immunoreactivity can be seen in normal hepatocytes compressed by the tumour nodule (arrowhead). In brain tissue, expression was negative for the normal tissue (Figure $5 \mathrm{Bg}$ ) but positive in this case for an atypical meningioma (Figure $5 \mathrm{Bh}$ ). Finally, in normal breast tissue, DESC1 expression was restricted to glands and duct epithelium to a lesser extent. Figure $5 \mathrm{Bi}$ represents a reactive breast tissue with a very weak expression surrounding a negative duct. With respect to tumours, a varied panorama of negative (Figure $5 \mathrm{Bj}$ ) and positive (Figures 5Bk and $\mathrm{l}$ ) DESC1 expression was observed (7 negative $v s 12$ positive cases). Moreover, expression in breast depended on the tumour histological type, being mainly restricted to ductal and lobular variants, but other additional factors may also contribute as not all of the ductal tumours analysed were positive. Additionally, two cases of ductal carcinoma in situ showed increased expression with respect to the corresponding infiltrating tumour. Data obtained from this immunohistochemistry analysis suggest that both up- and downregulation of DESC1 could be associated to cancer progression.

\section{DISCUSSION}

Proteolytic activities have been traditionally associated with the growth and expansion of different type of tumours. However, different serine proteases have been found downregulated in different types of human carcinomas. This is the case of DESC1, the expression of which inversely correlates with progression of head and neck tumours (Sedghizadeh et al, 2006). Our interest in this type of neoplasias prompted us to investigate the implication of DESC1 in cancer biology through the study of its activity, effect on invasiveness of a known cell model and the analysis of its expression in a variety of tumour tissues.

Common with most of the TTPS (Szabo et al, 2003) endogenous targets for human DESC1 remain unresolved. However, the production and purification of the recombinant catalytic domain of this protease has revealed for the first time that it exhibits a significant in vitro activity for substrates such as fibronectin, gelatin or fibrinogen. The ability to degrade extracellular matrix components has been observed in members of the TTSP family such as matriptase (Lee et al, 2000) or matriptase-2 (Velasco et al, 2002). This suggests that DESC1 could participate in the degradation of the extracellular matrix that occurs in normal and pathological conditions, including cancer. Likewise, DESC1 also shares with these two enzymes the capability for pro-uPA activation, revealing the possibility that DESC1 could participate in proteolytic cascades mediated by activated uPA.

Our initial results prompted us to use the full-length DESC1 in cell-based assays due to the fact that activity of the catalytic domain expressed in a bacterial host does not accurately reflect the enzyme activity in vivo. Moreover, the use of these types of assays does not remove the possible influence of the ancillary domains on the substrate specificity. We chose the dog kidney epithelial cell line MDCK, which have been widely used to attempt to elucidate the functional role in tumour processes of different proteins, including membrane-associated metalloproteases (Kadono et al, 1998; Kang et al, 2000). After the selection of two clones that expressed exogenous DESC1, we carried out three different types of assays. First, we observed an increase in the migration and motility properties of the clones that produce the protease, in a scrape-wound migration assay respecting to the control cells. Then, in matrigel-based invasion assays we found that MDCK/ DESC1 transfectants acquired an enhanced capacity to migrate and extravasate the collagen matrix, adopting a branched and elongated morphology. In a third type of assay, we showed of these cells to form branching extension in a 3D collagen lattice. The formation of this type of extensions represents a partial epithelial-mesenchymal transition, which could finally induce tubulogenesis (O'Brien et al, 2004). This is a phenotype relevant to renal development and carcinogenesis, and takes place concurrent with complex morphogenic processes that require cell proliferation and movement, rearrangements of the cytoskeleton and of the cell-cell junctional complexes, and remodelling of the cell matrix (Birchmeier et al, 2003). Results obtained in these assays evidence for the first time that DESC1 is a serine protease that could be involved in motility, cell growth and invasion processes.

Since DESC1 was identified as a gene downregulated in carcinomas of the head and neck, and the data obtained in this work indicate a possible involvement of this protease in the tumorigenic process, we carried out an immunohistochemical analysis of DESC1 expression in a variety of tissues of different origin. Although we could confirm this downregulation in larynx and pharynx tissues (not shown), the study revealed for the first time overexpression of DESC1 in a variety of carcinomas like kidney, brain and breast cancer. The up/downregulation for a particular protease among different types of cancers has been reported for other serine proteases, including some TTSPs. Thus, loss of testisin expression has been found in testicular tumorigenesis (Hooper et al, 1999), but its expression is associated with advanced stages of ovarian cancer (Shigemasa et al, 2000). Matriptase is upregulated in prostate and cervical cancer (Santin et al, 2003), but it is downregulated in advanced-stage ovarian tumours (Tanimoto et al, 2005). Hepsin has been described to promote cancer progression and metastasis in a mouse model (Klezovitch et al, 2004), but it seems to inhibit cell growth and invasion in prostate cancer cells (Srikantan et al, 2002). Moreover, we can not rule out that DESC1 could likewise be involved in proteolytic cascades that would include protease inhibitor as happens with matriptase (Netzel-Arnett et al, 2006). In this regard, the mouse counterpart of this protease, mDESC1, forms stable inhibitory complexes with both plasminogen activator inhibitor-1 and protein $\mathrm{C}$ inhibitor (Hobson et al, 2004). These observations raise new intriguing questions about the role of DESC1 in normal and pathological processes. To finally corroborate these data, further exhaustive functional studies and analysis of its expression in more tissues, including different histopathological parameters, would be needed to assess the final balance of DESC1 expression in each type of tissue. Moreover, we have shown in this study that the generated antibodies do not recognise the three serine protease domains of polyserase-1. However, it cannot be ruled out that these antibodies could recognise other TTPS, specially the closely related members of the HAT/DESC subfamily. Additionally, the generation of the mouse lacking this enzyme could contribute to shed light on the up- and downregulation of DESC1 in different tumours, and about its possible involvement in complex proteolytic cascades.

\section{ACKNOWLEDGEMENTS}

CG Viloria is a recipient of a postdoctoral fellowship from the Instituto Universitario de Oncología, which is supported by Obra Social Cajastur-Asturias and Red de Centros de CancerInstituto Carlos III, Spain. S Cal is recipient of a 'Ramon y Cajal' research contract. This work was supported by a grant from the Fondo de Investigaciones Sanitarias to MV González. We thank Marta Sánchez for excellent technical assistance, Dr Carlos López-Otín and Dr Roger Pickup for critical reading of the manuscript. 


\section{REFERENCES}

Afar DE, Vivanco I, Hubert RS, Kuo J, Chen E, Saffran DC, Raitano AB, Jakobovits A (2001) Catalytic cleavage of the androgen-regulated TMPRSS2 protease results in its secretion by prostate and prostate cancer epithelia. Cancer Res 61: 1686-1692

Behrens M, Bufe B, Schmale H, Meyerhof W (2004) Molecular cloning and characterisation of DESC4, a new transmembrane serine protease. Cell Mol Life Sci 61: 2866-2877

Birchmeier C, Birchmeier W, Gherardi E, Vande Woude GF (2003) Met, metastasis, motility and more. Nat Rev Mol Cell Biol 4: 915-925

Cal S, Quesada V, Garabaya C, Lopez-Otin C (2003) Polyserase-I, a human polyprotease with the ability to generate independent serine protease domains from a single translation product. Proc Natl Acad Sci USA 100: 9185-9190

Freije JM, Balbin M, Pendas AM, Sanchez LM, Puente XS, Lopez-Otin C (2003) Matrix metalloproteinases and tumor progression. Adv Exp Med Biol 532: $91-107$

Guipponi M, Vuagniaux G, Wattenhofer $M$, Shibuya K, Vazquez M, Dougherty L, Scamuffa N, Guida E, Okui M, Rossier C, Hancock M, Buchet K, Reymond A, Hummler E, Marzella PL, Kudoh J, Shimizu N, Scott HS, Antonarakis SE, Rossier BC (2002) The transmembrane serine protease (TMPRSS3) mutated in deafness DFNB8/10 activates the epithelial sodium channel $(\mathrm{ENaC})$ in vitro. Hum Mol Genet 11: $2829-2836$

Hobson JP, Netzel-Arnett S, Szabo R, Rehault SM, Church FC, Strickland DK, Lawrence DA, Antalis TM, Bugge TH (2004) Mouse DESC1 is located within a cluster of seven DESC1-like genes and encodes a type II transmembrane serine protease that forms serpin inhibitory complexes. J Biol Chem 279: 46981-46994

Hooper JD, Nicol DL, Dickinson JL, Eyre HJ, Scarman AL, Normyle JF, Stuttgen MA, Douglas ML, Loveland KA, Sutherland GR, Antalis TM (1999) Testisin, a new human serine proteinase expressed by premeiotic testicular germ cells and lost in testicular germ cell tumors. Cancer Res 59: $3199-3205$

Kadono Y, Shibahara K, Namiki M, Watanabe Y, Seiki M, Sato H (1998) Membrane type 1-matrix metalloproteinase is involved in the formation of hepatocyte growth factor/scatter factor-induced branching tubules in Madin-Darby canine kidney epithelial cells. Biochem Biophys Res Commun 251: $681-687$

Kang T, Yi J, Yang W, Wang X, Jiang A, Pei D (2000) Functional characterization of MT3-MMP in transfected MDCK cells: progelatinase A activation and tubulogenesis in 3-D collagen lattice. FASEB J 14: 2559- 2568

Klezovitch O, Chevillet J, Mirosevich J, Roberts RL, Matusik RJ, Vasioukhin $\mathrm{V}$ (2004) Hepsin promotes prostate cancer progression and metastasis. Cancer Cell 6: $185-195$

Lang JC, Schuller DE (2001) Differential expression of a novel serine protease homologue in squamous cell carcinoma of the head and neck. Br J Cancer 84: $237-243$

Lee SL, Dickson RB, Lin CY (2000) Activation of hepatocyte growth factor and urokinase/plasminogen activator by matriptase, an epithelial membrane serine protease. J Biol Chem 275: 36720-36725

List K, Haudenschild CC, Szabo R, Chen W, Wahl SM, Swaim W, Engelholm LH, Behrendt N, Bugge TH (2002) Matriptase/MT-SP1 is required for postnatal survival, epidermal barrier function, hair follicle development, and thymic homeostasis. Oncogene 21: $3765-3779$

List K, Szabo R, Molinolo A, Nielsen BS, Bugge TH (2006) Delineation of matriptase protein expression by enzymatic gene trapping suggests diverging roles in barrier function, hair formation, and squamous cell carcinogenesis. Am J Pathol 168: $1513-1525$

List K, Szabo R, Molinolo A, Sriuranpong V, Redeye V, Murdock T, Burke B, Nielsen BS, Gutkind JS, Bugge TH (2005) Deregulated matriptase causes ras-independent multistage carcinogenesis and promotes rasmediated malignant transformation. Genes Dev 19: 1934-1950
Netzel-Arnett S, Currie BM, Szabo R, Lin CY, Chen LM, Chai KX, Antalis TM, Bugge TH, List K (2006) Evidence for a matriptase-prostasin proteolytic cascade regulating terminal epidermal differentiation. J Biol Chem 281: $32941-32945$

Netzel-Arnett S, Hooper JD, Szabo R, Madison EL, Quigley JP, Bugge TH, Antalis TM (2003) Membrane anchored serine proteases: a rapidly expanding group of cell surface proteolytic enzymes with potential roles in cancer. Cancer Metastasis Rev 22: $237-258$

O’Brien LE, Tang K, Kats ES, Schutz-Geschwender A, Lipschutz JH, Mostov KE (2004) ERK and MMPs sequentially regulate distinct stages of epithelial tubule development. Dev Cell 7: 21-32

O’Brien LE, Zegers MM, Mostov KE (2002) Opinion: building epithelial architecture: insights from three-dimensional culture models. Nat Rev Mol Cell Biol 3: $531-537$

Overall CM, Lopez-Otin C (2002) Strategies for MMP inhibition in cancer: innovations for the post-trial era. Nat Rev Cancer 2: 657-672

Ridley AJ, Comoglio PM, Hall A (1995) Regulation of scatter factor/ hepatocyte growth factor responses by Ras, Rac, and Rho in MDCK cells. Mol Cell Biol 15: $1110-1122$

Santin AD, Cane S, Bellone S, Bignotti E, Palmieri M, De Las Casas LE, Anfossi S, Roman JJ, O'Brien T, Pecorelli S (2003) The novel serine protease tumor-associated differentially expressed gene-15 (matriptase/ MT-SP1) is highly overexpressed in cervical carcinoma. Cancer 98: $1898-1904$

Sedghizadeh PP, Mallery SR, Thompson SJ, Kresty L, Beck FM, Parkinson EK, Biancamano J, Lang JC (2006) Expression of the serine protease DESC1 correlates directly with normal keratinocyte differentiation and inversely with head and neck squamous cell carcinoma progression. Head Neck 28: $432-440$

Shigemasa K, Underwood LJ, Beard J, Tanimoto H, Ohama K, Parmley TH, O'Brien TJ (2000) Overexpression of testisin, a serine protease expressed by testicular germ cells, in epithelial ovarian tumor cells. J Soc Gynecol Investig 7: $358-362$

Srikantan V, Valladares M, Rhim JS, Moul JW, Srivastava S (2002) HEPSIN inhibits cell growth/invasion in prostate cancer cells. Cancer Res 62: $6812-6816$

Stanton H, Gavrilovic J, Atkinson SJ, d'Ortho MP, Yamada KM, Zardi L, Murphy G (1998) The activation of ProMMP-2 (gelatinase A) by HT1080 fibrosarcoma cells is promoted by culture on a fibronectin substrate and is concomitant with an increase in processing of MT1-MMP (MMP-14) to a $45 \mathrm{kDa}$ form. J Cell Sci 111(Part 18): 2789-2798

Szabo R, Netzel-Arnett S, Hobson JP, Antalis TM, Bugge TH (2005) Matriptase-3 is a novel phylogenetically preserved membrane-anchored serine protease with broad serpin reactivity. Biochem J 390: $231-242$

Szabo R, Wu Q, Dickson RB, Netzel-Arnett S, Antalis TM, Bugge TH (2003) Type II transmembrane serine proteases. Thromb Haemost 90: 185-193

Takeuchi T, Shuman MA, Craik CS (1999) Reverse biochemistry: use of macromolecular protease inhibitors to dissect complex biological processes and identify a membrane-type serine protease in epithelial cancer and normal tissue. Proc Natl Acad Sci USA 96: 11054-11061

Tanimoto H, Shigemasa K, Tian X, Gu L, Beard JB, Sawasaki T, O’Brien TJ (2005) Transmembrane serine protease TADG-15 (ST14/Matriptase/MTSP1): expression and prognostic value in ovarian cancer. Br J Cancer 92: $278-283$

Velasco G, Cal S, Quesada V, Sanchez LM, Lopez-Otin C (2002) Matriptase2, a membrane-bound mosaic serine proteinase predominantly expressed in human liver and showing degrading activity against extracellular matrix proteins. J Biol Chem 277: $37637-37646$

Yamaoka K, Masuda K, Ogawa H, Takagi K, Umemoto N, Yasuoka S (1998) Cloning and characterization of the cDNA for human airway trypsin-like protease. J Biol Chem 273: $11895-11901$

Yan W, Wu F, Morser J, Wu Q (2000) Corin, a transmembrane cardiac serine protease, acts as a pro-atrial natriuretic peptide-converting enzyme. Proc Natl Acad Sci USA 97: 8525-8529 